\title{
PENGARUH PAGAR TEMBOK TERHADAP TINGKAT KEBISINGAN PADA PERUMAHAN JALAN RATULANGI MAKASSAR
}

\author{
Sri umiati ${ }^{1}$
}

\begin{abstract}
ABSTRAK
Penelitian ini bertujuan untuk mengetahui tingkat kebisingan lalu lintas jalan Ratulangi Makassar dan juga mengetahui bagaimana pengaruh pagar tembok sebagai barier terhadap tingkat kebisingan pada halaman rumah jalan Ratulangi tersebut. Lokasi penelitian dilakukan pada dua lokasi, yaitu lokasi satu halaman tanpa pagar dan lokasi dua halaman dengan pagar tembok setinggi 2,0 meter yang keduanya terletak di jalan Ratulangi Makassar. Tiap lokasi dilakukan pengukuran pada dua titik ukur, yaitu titik ukur A dengan jarak 0 meter dari tepi badan jalan dan titik ukur B dihalaman rumah dengan jarak 7 meter dari tepi badan jalan, Pengukuran menggunakan dua buah alat ukur sound level meter yang dilakukan secara bersamaan. Tinggi pengukuran masing masing satu meter. Hasil penelitian diperoleh dengan membandingkan tingkat kebisingan yang terjadi pada lokasi satu dan lokasi dua. Dari penelitian diperoleh kesimpulan bahwa dengan adanya pagar penghalang tembok setinggi 2.0 meter, kebisingan menurun sebesar 9,27 dB(A) dibanding dengan kebisingan tanpa penghalang pagar. Kebisingan maximum ditepi jalan Ratulangi mencapai 92 $\mathrm{dB}(\mathrm{A})$. Kebisingan dengan suara tinggi terjadi pada saat konvoi kendaraan bermotor dan suara mobil ambulans yang melintas dijalan ini. Kebisingan rata-rata adalah sebesar $77 \mathrm{~dB}(\mathrm{~A})$.
\end{abstract}

Kata Kunci : kebisingan, lalu lintas, pagar tembok

\section{PENDAhuluan}

Makassar termasuk kota Metropolitan, luas areal $175.79 \mathrm{~km}^{2}$ dengan jumlah penduduk pada tahun 2006 berjumlah 1.112.688 jiwa. (sumber: Badan Pusat Statistik Makassar, 2006). Jalan Ratulangi Makassar adalah jalan arteri yang dilalui oleh kendaraan besar, angkutan kota dan dekat dengan area perdagangan. Kesibukan lalu lintas dijalan ini dimulai pukul 4.30 pagi hingga 24.00 malam. Banyaknya kendaraan yang melintas setiap harinya menyebabkan kebisingan yang cukup tinggi. Bising dalam waktu yang cukup lama dapat menimbulkan gangguan kesehatan dan kenyamanan terutama bagi masyarakat yang tinggal disepanjang jalan tersebut. Bising dalam waktu yang cukup lama dapat menimbulkan gangguan kesehatan dan kenyamanan manusia. Gangguan itu berupa: gangguan pendengaran, gangguan komunikasi, gangguan kualitas tidur, gangguan psikologis, gangguan konsentrasi dan produktivitas kerja. SK Menteri Negara Lingkungan Hidup No: Kep 48/MENLH/XI/1996, tanggal 25 November 1996 menyebutkan tentang kriteria batas tingkat kebisingan. Bahwa untuk daerah pemukiman tingkat kebisingan maksimum untuk outdoor yang diyaratkan adalah sebesar $55 \mathrm{~dB}(\mathrm{~A})$.

Beberapa pertanyaan yang akan mendukung penelitian in adalah:

1. Berapa dB(A) tingkat kebisingan di tepi jalan Ratulangi Makassar?

2. Bagaimana pengaruh pagar tembok setinggi 2 meter terhadap tingkat kebisingan pada halaman rumah jalan Ratulangi tersebut?

\footnotetext{
${ }^{1}$ Dosen Jurusan Teknik Sipil Fakultas Teknik Universitas Andalas
} 


\section{TINJAUAN PUSTAKA}

\subsection{Bunyi}

Bunyi (sound) adalah sesuatu yang terdengar oleh telinga yang berasal dari benda yang bergetar. Bunyi dapat didengar oleh manusia memerlukan tiga aspek yang harus ada dalam waktu bersamaan yaitu: sumberbunyi, medium penghantar gelombang bunyi, dan telinga. Di udara terbuka penurunan Intensitas bunyi berbanding terbalik dengan kelipatan jarak dari sumber bunyi. Intensitas bunyi berkurang $3 \mathrm{~dB}$ setiap pelipatan jarak. Gambar 1. memperlihatkan selisih tingkat kebisingan antara dua lokasi dengan rasio jarak yang berbeda dari sumber bising ke pendengar pada udara terbuka.

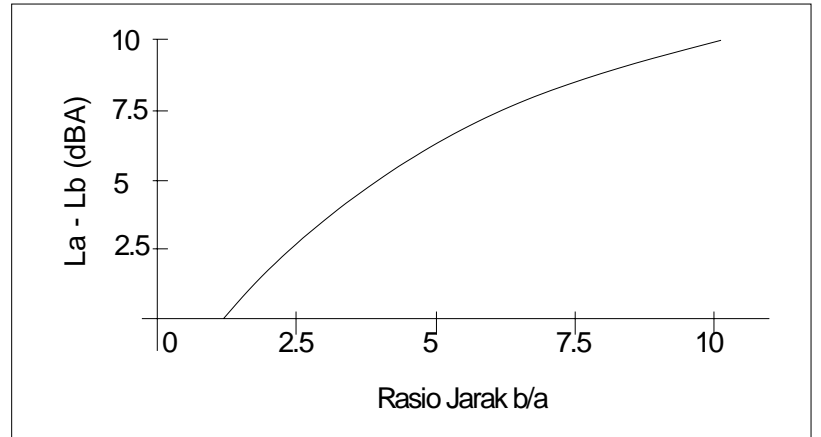

\section{Gambar 1. Hubungan Selisih Tingkat Kebisingan Dan Rasio Jarak (Sumber: Wilson.C.E)}

\subsection{Kebisingan}

1. Pengertian Kebisingan: Mentri Negara Lingkungan Hidup dalam Keputusan Mentri LH (1996) menyatakan kebisingan adalah suara yang tidak diinginkan dari usaha atau kegiatan dalam tingkat dan waktu tertentu yang dapat menimbulkan gangguan kesehatan manusia dan kenyamanan lingkungan

2. Ambang Batas Kebisingan: Adalah batas maksimal tingkat kebisingan yang diizinkan. Keputusan Menteri Lingkungan Hidup no Kep 48 /MENLH/11/1996 menetapkan batas maksimal tingkat kebisingan yang diperbolehkan dibuang ke lingkungan hingga tidak menimbulkan gangguan kesehatan manusia dan kenyamanan lingkungan. Khusus untuk perumahan pemukiman batas maximum out door ditetapkan sebesar $55 \mathrm{~dB}(\mathrm{~A})$

\subsection{Kebisingan Lalu Lintas}

Kebisingan lalu lintas adalah kebisingan yang ditimbulkan oleh pergerakan kendaraan berat seperti truk, bus, juga mobil penumpang di jalan raya. Bising yang dikatakan sudah mengganggu menurut menteri lingkungan hidup adalah: tingkat kebisingan $67 \mathrm{dBA}$ dan lama waktu paparan terjadi selama beberapa jam berturut-turut dalam satu hari, baik pada waktu siang atau malam hari (Tabel 1).

Tabel 1. Kriteria Daerah Bising (KDB) dan waktu paparan perhari

\begin{tabular}{ccc}
$\begin{array}{c}\text { Tingkat Kebisingan } \\
\text { (dBA) }\end{array}$ & $\begin{array}{c}\text { Waktu paparan } \\
\text { /hari }\end{array}$ & $\begin{array}{c}\text { Waktu paparan } \\
\text { malam }\end{array}$ \\
\hline $60-65$ & 12 jam/hari & 3 jam /hari \\
$65-75$ & 10 jam/hari & $3 \mathrm{jam} / \mathrm{hari}$ \\
$75-90$ & $10 \mathrm{jam} / \mathrm{hari}$ & - \\
\hline
\end{tabular}

\section{2| JURNAL REKAYASA SIPIL}




\subsection{Bangunan Peredam Bising}

Bangunan Peredam Bising adalah bangunan penghalang pada jalur perambatan suara dengan bentuk dan bahan tertentu yang diperuntukan sebagai alat untuk menurunkan tingkat kebisingan yang diakibatkan oleh lalu lintas kendaraan bermotor (Badan Litbang PU Dep PU). Kinerja bangunan peredam bising dipengaruhi oleh panjang dan tinggi bangunan, sifat transmitif, reflektif, atau absorptif dari materialnya. Bahan penghalang bising buatan dapat dibuat dengan menggunakan kayu, panel beton pracetak, beton ringan berongga (aerated), panel fiber semen, panel acrylic transparan atau baja profil (Gambar 2.).

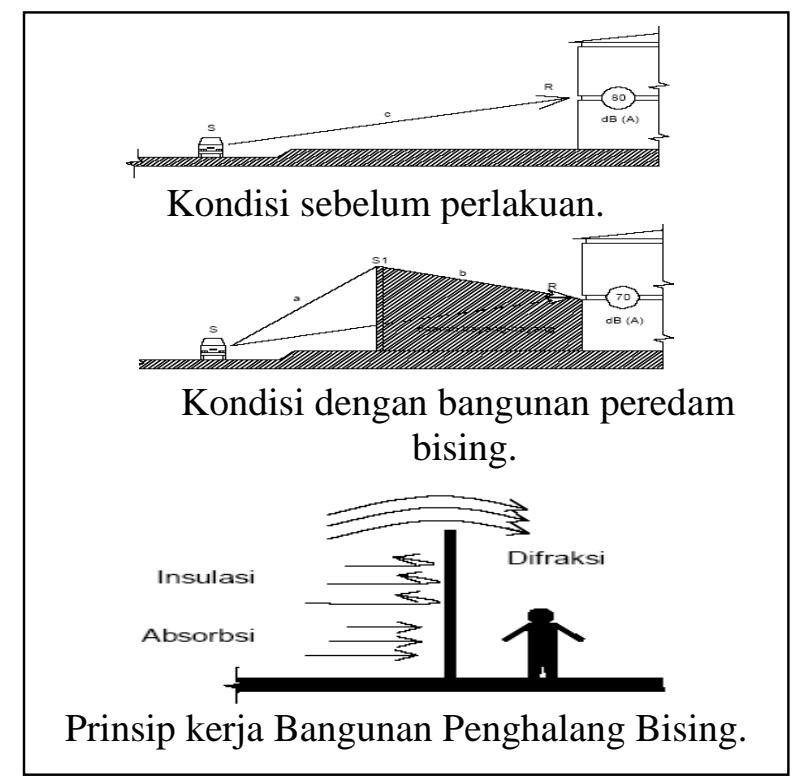

Gambar 2. Bangunan Peredam Bising

(Badan Litbang PU Departemen PU)

\section{METODE PENELITIAN}

\subsection{Lokasi Penelitian}

Penelitian dilakukan di jalan Ratulangi Makassar. Lokasi terpilih adalah dua lokasi halaman yang berhadapan langsung dengan jalan raya, yaitu halaman tanpa pagar dan halaman dengan pagar setinggi 2 meter. Batas sepadan $10 \mathrm{~m}$, luas halaman masing masing $10 \times 15 \mathrm{~m}^{2}$

\subsection{Tinggi dan Jarak Pengukuran.}

Pada tiap lokasi, pengukuran kebisingan dilakukan dengan menggunakan dua buah alat ukur sound level meter secara bersamaan pada dua titik ukur, titik ukur A ditempatkan pada jarak 0 meter dari tepi badan jalan dan titik ukur B ditempatkan dihalaman rumah dengan jarak 7 meter dari tepi badan jalan. Untuk dapat membandingkan tingkat kebisingan pada kedua lokasi tersebut maka pengukuran harus dilakukan dengan jarak dan ketinggian yang sama. Ukuran ketinggian ditetapkan masing-masing satu meter. Sumber bising adalah suara kendaraan bermotor yang melintas dijalan Ratulangi. 


\subsection{Waktu Penelitian}

Penelitian dilaksanakan pada dua lokasi selama 2 hari,waktu pengukuran: Pukul 7.00, hingga pukul 20.00 WITA (Waktu Indonesia Tengah)

\subsection{Alat yang Digunakan}

1) 2 buah alat pengukur kebisingan (Sound Level Meter)

Dengan spesifikasi alat: Sound Level Meter Tipe IEC651, ANSI

a) Frequency range: $31.5 \mathrm{~Hz} \sim 8 \mathrm{KHz}$.

b) Rentang pengukuran : $35 \mathrm{~dB} \sim 130 \mathrm{~dB}$.

c) Frekuensi bobot: A / C

2) Meteran untuk mengukur jarak, panjang, lebar dan tinggi.

3) Kamera untuk pemotretan obyek pengamatan.

4) Komputer untuk mengolah data

\section{HASIL PENGUKURAN}

Dari hasil pengukuran yang dilakukan dilapangan diperoleh nilai kebisingan tertinggi, terendah dan nilai rata rata-rata dapat dilihat pada Tabel 2:

\subsection{Kebisingan Lokasi Satu}

Tabel 2. Kebisingan Lokasi I

\begin{tabular}{|c|c|c|c|c|c|}
\hline \multirow{2}{*}{$\begin{array}{c}\text { Waktu } \\
\text { Pengukuran }\end{array}$} & \multirow{2}{*}{$\begin{array}{c}\text { Titik } \\
\text { Pengukuran }\end{array}$} & \multicolumn{3}{|c|}{ Kebisingan $\quad \mathrm{dB}(\mathrm{A})$} & \multirow{2}{*}{$\begin{array}{l}\text { Selisih rata } \\
\text { rata } \mathrm{dB}(\mathrm{A})\end{array}$} \\
\hline & & Tertinggi & Terendah & Rata rata & \\
\hline \multirow{2}{*}{ Jam 7.00} & $\mathrm{~A}$ & 80 & 65 & 72,2330 & \\
\hline & $\mathrm{B}$ & - & - & - & \\
\hline \multirow{2}{*}{ Jam 8.00} & $\mathrm{~A}$ & 87 & 65 & 73,89 & \multirow{2}{*}{5,42} \\
\hline & $\mathrm{B}$ & 80 & 57 & 68,47 & \\
\hline \multirow{2}{*}{ Jam 9.00} & A & 89 & 72 & 79,4 & \multirow{2}{*}{4,35} \\
\hline & $\mathrm{B}$ & 85 & 67 & 70,05 & \\
\hline \multirow{2}{*}{ Jam 10.00} & A & 86 & 72 & 79.35 & \multirow[b]{2}{*}{4,55} \\
\hline & $\mathrm{B}$ & 83 & 68 & 74,8 & \\
\hline \multirow{2}{*}{ Jam 11.00} & $\mathrm{~A}$ & 90 & 71 & 78,23 & \multirow[b]{2}{*}{4,27} \\
\hline & $\mathrm{B}$ & 89 & 67 & 73,96 & \\
\hline \multirow{2}{*}{ Jam 12.00} & $\mathrm{~A}$ & 84 & 71 & 77,04 & \multirow[b]{2}{*}{5.41} \\
\hline & $\mathrm{B}$ & 81 & 65 & 71.62 & \\
\hline \multirow{2}{*}{ Jam 14.00} & A & 85 & 72 & 77,52 & \multirow[b]{2}{*}{5,48} \\
\hline & $\mathrm{B}$ & 79 & 65 & 72,05 & \\
\hline \multirow{2}{*}{ Jam 16.00} & $\mathrm{~A}$ & 89 & 69 & 76,72 & \multirow[b]{2}{*}{4,88} \\
\hline & $\mathrm{B}$ & 79 & 65 & 71,84 & \\
\hline \multirow{2}{*}{ Jam 18.00} & $\mathrm{~A}$ & 86 & 70 & 77,4 & \multirow[b]{2}{*}{-} \\
\hline & - & - & - & - & \\
\hline \multirow{2}{*}{ Jam 20.00} & A & 87 & 69 & 78,2 & \multirow[b]{2}{*}{-} \\
\hline & - & - & - & - & \\
\hline \multicolumn{5}{|c|}{ Selisih rata rata } & 4,91 \\
\hline
\end{tabular}

Keterangan : $\mathrm{A}=0$ meter dari tepi badan jalan $\mathrm{B}=$ Halaman 7 meter dari tepi badan jalan Pengambilan data : 6-6-2010 
Kebisingan maximum dengan suara tertinggi terjadi pada saat konvoi kendaraan bermotor, suara mobil ambulans dan mobil polisi lalu lintas yang sering melintas di jalan ini

\section{Regresi Lokasi Satu}

Untuk mengetahui gambaran hubungan antara kebisingan tepi jalan dan kebisingan halaman digunakan sebaran titik dan kurva linear.Variabel $\mathrm{X}$ adalah kebisingan tepi jalan dan variable $\mathrm{Y}$ adalah kebisingan halaman (Gambar 3).

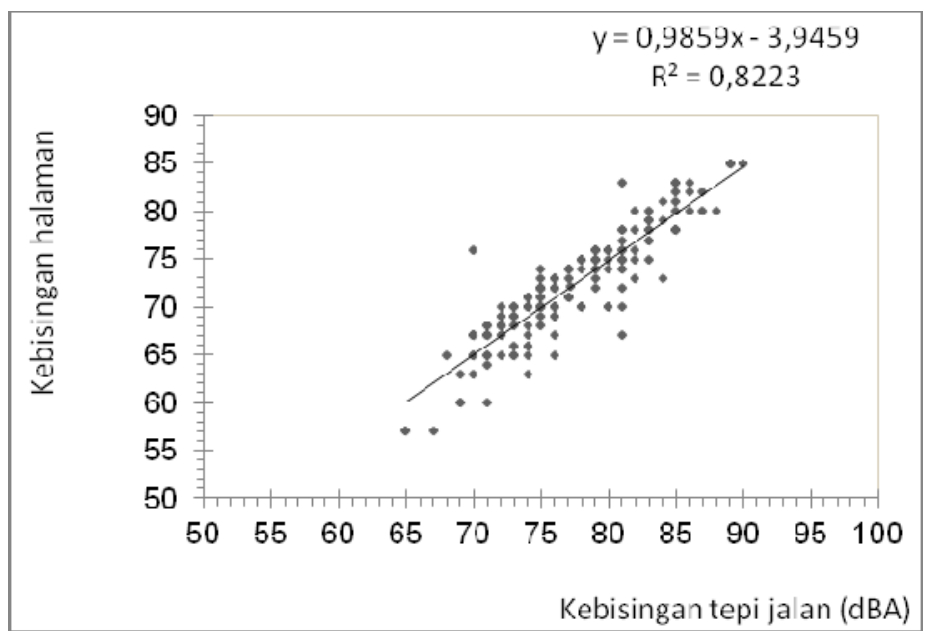

Gambar 3. Hubungan Kebisingan Tepi Jalan (Titik A) Dan Halaman (Titik B) Lokasi 1

\subsection{Kebisingan Lokasi Dua}

Pengambilan data yang dilakukan pada tanggal 12 Juni 2010 menghasilkan data seperti yang terlihat pada Tabel 3 .

Tabel 3. Tingkat KebisinganLokasi 2

\begin{tabular}{|c|c|c|c|c|c|}
\hline \multirow[b]{2}{*}{$\begin{array}{c}\text { Waktu } \\
\text { Pengukuran }\end{array}$} & \multicolumn{5}{|c|}{ Kebisingan $\mathrm{dB}(\mathrm{A})$} \\
\hline & $\begin{array}{c}\text { Titik } \\
\text { Pengukuran }\end{array}$ & Tertinggi & Terendah & Rata rata & $\begin{array}{c}\text { Selisih rata } \\
\text { ratatitik } 1 \text { dan } 2 \\
\text { dB }\end{array}$ \\
\hline \multirow[b]{2}{*}{ Jam 7.00} & $\bar{A}$ & 90 & 67 & 78.5 & \\
\hline & B & - & - & - & \\
\hline \multirow[b]{2}{*}{ Jam 8.00} & A & 89 & 65 & 77.7 & \\
\hline & B & 78 & 55 & 63,6 & 14,1 \\
\hline \multirow{3}{*}{ Jam 9.00} & $\mathrm{~A}$ & 92 & 71 & 78,4 & \\
\hline & B & 75 & 56 & 64.5 & 13,9 \\
\hline & A & 92 & 67 & 78.0 & \\
\hline Jam 10.00 & B & 80 & 50 & 62.6 & 15,4 \\
\hline \multirow[b]{2}{*}{ Jam 11.00} & A & 92 & 67 & 78,2 & \\
\hline & B & 80 & 50 & 64,5 & 14,7 \\
\hline \multirow[b]{2}{*}{ Jam 12.00} & A & 84 & 66 & 74,1 & \\
\hline & B & 75 & 53 & 61,7 & 13,4 \\
\hline \multirow[b]{2}{*}{ Jam 14.00} & A & 88 & 65 & 77.2 & \\
\hline & B & 79 & 53 & 60.3 & 12.9 \\
\hline
\end{tabular}




\begin{tabular}{llcccc}
\hline & A & 89 & 69 & 76.9 & \\
Jam 16.00 & B & 78 & 54 & 61.2 & 15.7 \\
\hline & A & 89 & 69 & 76.4 & \\
Jam 18.00 & B & - & - & - & \\
\hline \multirow{2}{*}{ Jam 20.00} & A & 87 & 64 & 75.7 & \\
\hline & B & - & - & - & \\
& & & Selisih rata-rata & \multirow{2}{*}{$\mathbf{4 , 3}$} \\
\hline
\end{tabular}

Keterangan $\mathrm{A}=0$ meter dari tepi badan jalan $\mathrm{B}=$ Halaman 7 meter dari tepi badan jalan

\section{Regresi Lokasi Dua}

Hubungan antara nilai kebisingan di tepi jalan dan halaman pada lokasi 2 dapat dilihat pada Gambar 4.

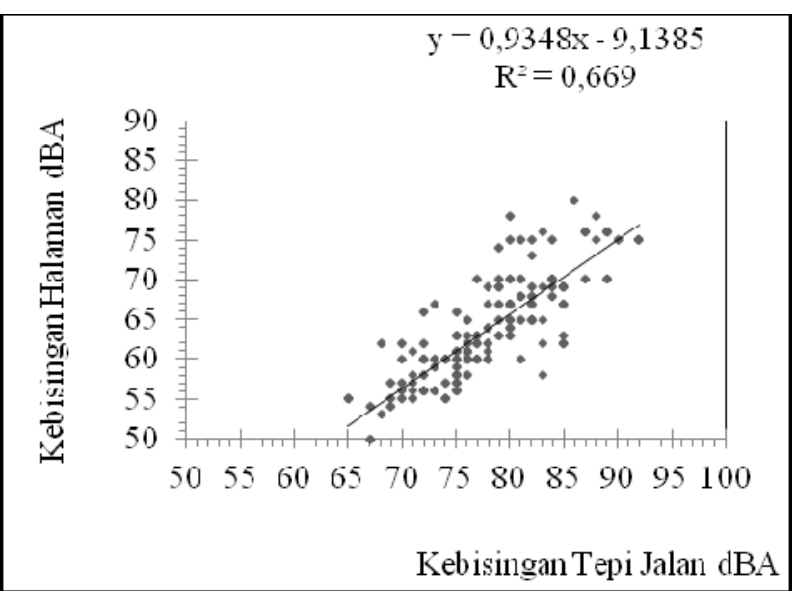

\section{Gambar 4. Hubungan Kebisingan Tepi Jalan (Titik A) dan Halaman (Titik B) Pada Lokasi 2}

\section{Hubungan Kurva Regresi Lokasi Satu dan Dua}

untuk mendapatkan gambaran yang lebih jelas selisih antara tingkat kebisingan pada halaman lokasi satu dan lokasi dua dibuat pula kurva hubungan regresi lokasi satu dan dua, hasilnya seperti terlihat pada Gambar 5.

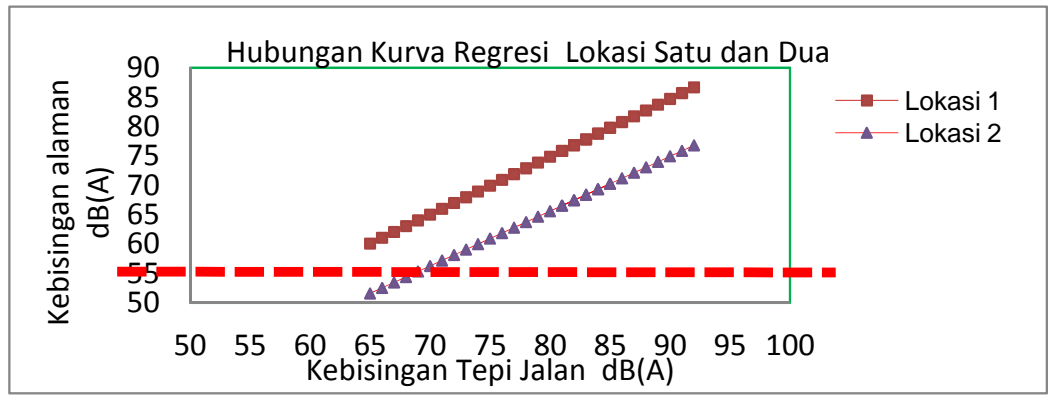

Gambar 5. Hubungan Kurva Regresi Lokasi Satu dan Lokasi Dua

\section{6| J URNAL REKAYASA SIPIL}


Dari Gambar 3 - 5. dapat dijelaskan bahwa:

1. Kebisingan jalan Ratulangi yang diukur jam 7.00 - 20.00 WITA, tanggal 6-6-2010 dan12-62010 adalah sebesar rata-rata $77 \mathrm{~dB}(\mathrm{~A})$. Minimum $65 \mathrm{~dB}(\mathrm{~A})$ dan Maximum $92 \mathrm{~dB}(\mathrm{~A})$.

2. Kebisingan $65 \mathrm{dBA}$ ditepi jalan menghasilkan bising pada halaman lokasi tanpa pagar pembatas (lokasi satu) sebesar rata rata 60,08 dBA. dan pada halaman lokasi dengan pagar pembatas setinggi 2 meter (lokasi dua) sebesar $51 \mathrm{dBA}$, sehingga terjadi selisih kebisingan sebesar 9,02 $\mathrm{dB}(\mathrm{A})$.

3. Dengan meningkatnya kebisingan tepi jalan hingga 92 dBA meningkatkan bising dihalaman lokasi satu sebesar 86,76 dBA dan bising pada halaman lokasi dua sebesar $76 \mathrm{~dB}(\mathrm{~A}$.)

\section{KESIMPULAN}

1. Pagar tembok setinggi 2 meter berhasil menurunkan kebisingan halaman sebesar rata rata 9,02 dBA.

2. Kebisingan halaman pada lokasi dua yang berhasil turun hingga mencapai $76 \mathrm{~dB}(\mathrm{~A})$ pada saat kebisingan tepi jalan sebesar $92 \mathrm{~dB}(\mathrm{~A})$, masih diatas ambang yang diizinkan oleh Menteri lingkungan hidup yakni kebisingan outdoor untuk lingkungan perumahan sebesar 55dB(A).

Perumahan yang terletak disepanjang jalan raya dengan tingkat kebisingan yang tinggi untuk menurunkan tingkat kebisingan sebaiknya pagar pembatas tembok dan dikombinasikan dengan tanaman berdaun lebat yang dapat mereduksi kebisingan.

\section{DAFTAR KEPUSTAKAAN}

Badan Pusat Statistik Makassar, (2007), “Makassar dalam angka 2006”.

Departemen Pekerjaan Umum, Badan Litbang, (2006), "Pedoman Mitigasi Dampak Kebisingan Akibat Lalu Lintas Jalan".

Departemen Pekerjaan Umum, Direktorat Jenderal Bina Marga, (1999),"Perencanaan Teknik Bangunan Peredam Bising".

Wilson C.E, (1989), "Noise Control Measurement, Analysis, and Control of Sound and Vibration”. 
Pengaruh Pagar Tembok Terhadap Tingkat Kebisingan Pada Perumahan Jalan Ratulangi Makassar

28| JURNAL REKAYASA SIPIL 